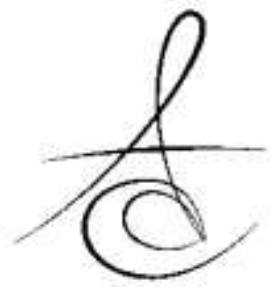

\title{
DENTİNİN BİYOMİMETİK REMİNERALİZASYONU
}

\author{
BIOMIMETIC REMINERALIZATION OF DENTIN
}

Makale Kodu/Article code: 3634

Makale Gönderilme tarihi: 13.04 .2018

Kabul Tarihi: 31.05 .2018

DOI : $10.17567 /$ ataunidfd. 428925
Z.Aslı Güçlü Özkaya: ORCID ID: 0000-0003-0453-0167

Zekiye Hidayet: ORCID ID: 0000-0001-5621-5279

\section{öz}

Demineralizasyon durumlarında diş sert dokularının remineralize edici materyaller ile tedavisi non-invaziv bir teknik olması nedeniyle artan ilgi görmektedir. Yüzeyel diş dokusunun başlangıç çürüğünde olduğu gibi demineralize dentinin de remineralizasyonun sağlanabileceği yapılan çalışmalarda gösterilmiştir. Ancak dentinin organik yapısı nedeniyle remineralizasyonunun mineye oranla daha karmaşık olduğu bildirilmiştir. Mine ve dentin dokusu arasındaki yapısal farklılıkar dentinin remineralizasyonunda kullanılacak yeni materyallerin geliştirilmesi gerekliliğini doğurmuştur. Literatürde konuyla ilgili farklı materyallerin kullanıldığı çok sayıda çalışma mevcuttur. Bu derlemede, dentinin biyomimetik remineralizasyonunun mekanizması açıklanarak konuyla ilgili geliştirilen yeni materyallerle ilgili bilgi verilmiştir.

Anahtar kelimeler: dentin, biyomimetik remineralizasyon, materyaller

\section{SUMMARY}

In recent years, remineralization applications have an increasing attention due to their succesfull potential on non-invasive treatment. Studies showed remineralization also be possible on dentinal tissue like emanel tissue. Remineralization of demineralized dentin is complicated to enamel remineralization process due to the complex structure of the dentin. This difference cause different approaches on remineralizaton of dentin and enamel; new materials and applications have been investigating for biomimetic remineralization of demineralized dentin until today. This paper reviewed the mechanisms of biomimetic dentin remineralization and concepts in development of mineralization materials.

Key words: dentin, biomimetic remineralization, materials

*Erciyes Üniversitesi, Diş Hekimliği Fakültesi, Pedodonti A.D, Kayseri, Turkey

Kaynakça Bilgisi: Güçlü Özkaya Za, Hidayet Z. Dentinin Biyomimetik Remineralizasyonu. Atatürk Üniv Diş Hek Fak Derg 2020; 30: 156-166. Citation Information: Güçlü Özkaya Za, Hidayet Z. Biomimetic Remineralization of Dentin. J Dent Fac Atatürk Uni 2020; 30: 156-166.

\section{GİRİ̧̧}

Son yıllarda remineralizasyon uygulamaları, terapötik önemi kabul edilen non-invaziv bir tedavi olarak artan bir ilgi görmektedir ${ }^{1}$. Yüzeyel diş dokusunun başlangıç çürüğünde olduğu gibi demineralize dentinin de remineralizasyonunu sağlayacak materyallerin geliştirilmesi üzerinde durulmaktadır². Demineralize veya çürük dentinde inorganik mineral benzeri materyaller yoluyla minerallerin geri kazanılması işlemi "biyomimetik remineralizasyon" olarak adlandırımaktadır $^{3}$. Biyomimetik remineralizasyonun avantajı, demineralize dentinin radikal uygulamalara maruz kalmadan kaybedilen mineral kristallerinin doğal oluşum süreci taklit edilerek dentin kompleks yapısının tekrar oluşturulmasıdır. Bu nedenle dentinin biyomimetik remineralizasyonu ile ilgili basamakların daha iyi anlaşılması üzerinde çalışılan konulardandır ${ }^{4}$.

$\mathrm{Bu}$ derlemenin amacl; dentinin biyomimetik remineralizasyon mekanizmasının açıklanarak konuyla ilgili geliştirilen yeni materyallerin incelenmesidir.

\section{Demineralize Dentinin Biyomimetik}

\section{Remineralizasyon Mekanizması}

Diş çürümesinde oral bakteriler, diyetle alınan karbonhidratları metabolize ederek oluşturdukları 
asidik ürünlerle dişin sert dokularındaki minerallerin çözülmesine ve nihayetinde yapısal matriksin yok olmasına neden olmaktadır. Dentindeki apatit kristalleri minedekilere oranla çok daha küçük bir kristal boyuta ve daha yüksek karbonat içeriğine sahiptir. Bu nedenle asitlere maruz kaldığında demineralizasyonu mine apatitinden daha fazla ve hızlı olmaktadır ${ }^{5}$. Çürükten etkilenmiş ve demineralize olmuş fakat enfekte olmayan dentin, fizyolojik olarak mineralize edilebilir niteliktedir. Ancak dikkat edilmesi gereken önemli nokta; dentinin yüksek organik içeriği nedeniyle remineralizasyonunun mineye göre çok daha karmaşık bir süreç olduğudur ${ }^{6,7}$.

Mine ile dentin remineralizasyonu arasındaki farklııklar yapıların kendilerine özgü olan özelliklerinden kaynak- lanmaktadır. Bundan dolayı iki farkı yapının ideal remineralizasyonundan beklenen sonuclar aynı değildir. Başlangıç mine lezyonun remineralizasyonundan demineralize olmuş dokuya mineralin geri kazandırıması ve çürüklere karşı daha dirençli alanların elde edilmesi beklenirken demineralize dentinin remineralizasyonundan, özellikle intrafibriller hidroksiapatit oluşturulmasıyla kollajen matriksinin remineralize edilmesi, açık dentin tübüllerinin tıkanması ve dentin mikro yapısının yeniden organize edilmesi beklenmektedir ${ }^{8}$. Dentin - pulpa kompleksini korumak için doğal mine ile benzer şekilde dentin yüzeyini örten ve bağ- lanan minerallerin çökelmesi arzu edilmektedir. Tüm bu nedenlerden dolayı dentin benzeri dokunun remi- neralizasyonu veya rejenerasyonu, in vivo veya in vitro ortamda mine benzeri dokuların remineralizasyonu veya rejenerasyonundan daha zordur ${ }^{9,10}$.

Demineralize dentinin biyomimetik remineralizasyonu, uygun koşullarda inorganik mineralin lezyon yüzeyine çökelmesinden farklı olarak gerçekleşen organik matris aracilıklı bir remineralizasyondur. Organik matriks aracilı remineralizasyonun en önemli özelliği ise matriks-mineral ara yüzünde molekülerin etkileşimleriyle oluşan çekirdeklenme bölgelerinin yönlendirilmesidir ${ }^{11}$. Çekirdeklenme bölgeleri, demineralize dentinin kollajen matrisindeki artık kristallerin remineralizasyona öncülük ettiği alanlar olarak tanımlanmaktadır. Tamamen ve kısmen demineralize dentin arasındaki belirgin fark, çekirdeklenme merkezi olarak işlev görebilen kalan apatit kristallerinin varlığıdır. Böylece, kısmen demineralize edilmiş bir kollajen matriksinin remineralizasyonu tamamen demineralize kollajen matriksine göre daha kolay olmaktadır ${ }^{12}$. Dentin matriksinin organik kısmı, ağılıkı olarak Tip I kollajen ve mineral ile takviye edilmiş üç boyutlu bir matriks oluşturan non-kollojenik proteinlerden oluşmaktadır ${ }^{13}$. İnorganik kısmı ise kollajen fibrillerindeki konumuna göre adlandırımış olan karbonatlı nano kristalin hidroksiapatit oluşturmaktadır. Dentinde hidroksiapatitin, fibriller içinde (intrafibriller mineral) ve fibriller arasında (ekstrafibriller mineral) iki özel bölgede oluştuğu gösterilmiştir. Ekstrafibriller hidroksiapatit kollajen fibrillerini ayıran boşluklarda bulunurken, intrafibriller hidroksiapatit genellikle tropokollagen molekülleri arasında uzanan fibrillerin boşluk bölgelerinde olduğu düşünülmektedir ${ }^{14,15}$. İntrafibriller mineralin dokunun doğal mekanik özelliklerini gösterebilmesi adına önemli olduğu öne sürülmüştür ${ }^{3,16}$.

Yakın tarihli araştırmalarda, intrafibriller mineral yokluğunda dentinin mineral içeriği ve mekanik özellikleri arasındaki beklenen doğrusal ilişkinin doku hidrate hale getirildiğinde kaybolduğuna dair önemli deliller sağlanmıştır. Bu çalışmalarda, etkilenen dentinin mekanik işlevselliğinin yeniden kurulabilmesi için hidrate koşullar altında sadece ekstrafibriller olarak değil intrafibriller boşluk bölgelerinde de mineral geri alımının olması gerektiği bildirilmiştir ${ }^{16-18}$. Bu nedenle; demineralize dentinin tedavisinde kritik nokta yalnızca kaybolan minerali yerine koymak değil aynı zamanda alınan mineralin, demineralize matriks ile etkili bir şekilde birleştirilmesi ile dokunun mekanik özelliklerinin iyileştirilmesidir. ${ }^{3}$ Matriks ile bağlanmamış yüksek konsantrasyonda mineral matriks içinde yüzeceğinden, kollajen yapı yük altında kaldığı zaman yeteri kadar destek olamaz. Bu durumda kollajenin deforme olma intimalinin yüksek olduğu, dentinin fonksiyonel ve mekanik özelliklerinde anlamlı düşüşler olduğu tespit edilmiştir. Bununla birlikte; eğer mineral matrikse bağlanır ve kollajen yapıyı takviye ederse o zaman matriksin özelliklerinin doğal dentin matriksine benzediği gösterilmiştir. 3,19,20.

Dentinin kalitesi; dokunun ana özelliklerini etkileyen mikro yapı, mineral yoğunluğu ve özellikle mineralin organik yapıdaki yeri gibi faktörlerin toplamına bağlıdır. Bu nedenle; remineralize edilmiş dokular değerlendirilirken sadece mineral yoğunluğu açısından değil aynı zamanda fizyolojik hidrasyon koşullarında matriksin organik ve inorganik bileşenleri arasındaki etkileşimi yansıtan mekanik özelliklerinin de değerlendirilmesini gerekmektedir ${ }^{3,21}$.

Demineralize dentinin remineralizasyonu sonrasında biyolojik ve mikro yapısal değişikliklerin daha iyi anlaşılmasına yönelik çok sayıda araştırma yapılmıştır. Yapılan çalışmalar, mineralin demineralize dentin mat- 
riksi içine yeniden dâhil olduğunu bildirmiş olup başarı bulgusu çoğunlukla fizyolojik hidrasyon koşullarında mineral matriks bağlanmasının değerlendirilmesine ve dokunun mekanik özelliklerinin iyileştirilmesine bakılmaksızın dokunun ne kadar çok minerali geri kazandığının değerlendirilmesine dayanmaktadır 3,10,22-25.

\section{DENTİNİN BİOMIMMETIK REMİNERALİZASYO- NUNDA KULLANILAN MATERYALLER}

Çürük dentinin remineralizasyonu ya oral sıvıda demineralize dokudan salınmış olan iyonların (kalsiyum, fosfat ve fluorid) spontan bir şekilde çökelmesi ya da aynı iyonları içeren materyallerin tedavi amacıyla uygulanmasıyla oluşabilmektedir ${ }^{26}$. Demineralize dentinin remineralizasyonu ile ilgili günümüze kadar yapılmış olan çalışmalarda kullanılan materyalleri aşağıda topluca görebilmekteyiz.

1. Fluorohidroksiapatit Jel ${ }^{27}$

2. Nano Hidroksiapatit ${ }^{28}$

3. Kalsiyum Fosfat ${ }^{29}$

a. Nano - $\beta$ - Trikalsiyum Fosfat ${ }^{25}$

b. Amorf Kalsiyum Fosfat (ACP) ${ }^{11}$

b.1. Kazein Fosfopeptid - Amorf Kalsiyum Fosfat (CPP - ACP) 23,30

b.2. Nanopartiküllü Amorf Kalsiyum Fosfat Kompozitler ${ }^{31}$

4. Kalsiyum Silikat ${ }^{32,33}$

5. Fonksiyonel Biyomimetik Analoglar ${ }^{34}$
a. Poliakrilik asit (PAA) ${ }^{35,36}$
b. Polivinilfosfonik asit (PVPA) $)^{35,37}$
c. Sodyum trimetafosfat (STMP) 38,39
d. PAMAM ( Poliamido amin) ${ }^{31,40}$
e. Agaroz Hidrojel ${ }^{9,11}$
f. L-Glutamik Asit ( L- Glu $)^{41}$
g. Dentin Matriks Proteini - 1 (DMP - 1)
türevi sentetik oligopeptitler ${ }^{42}$
h. Fosforilize Kitozan (P-chi) ${ }^{4}$

6. Biyoaktif Cam ${ }^{10}$

7. Çinko Klorid ve Çinko Oksit ${ }^{43}$

\section{Fluorohidroksiapatit Jel}

Fluorohidroksiapatit (FHA) jel sistemi; kalsiyum nitrat $\left(\mathrm{Ca}\left(\mathrm{NO}_{3}\right)_{2}\right)$, potasyum dihidrojen fosfat $\left(\mathrm{KH}_{2} \mathrm{PO}_{4}\right)$, potasyum fluorür (KF), deiyonize su ve agaroz içermektedir. FHA jelin, derin çürüklerde dentin üzerinde apatit yapılar oluşturabileceği ve kalsiyum fosfat iyonlarının agaroz hidrojelinden dentin yüzeyine doğru yönlendirilmiş difüzyona uğramasıyla remineralizasyonu teşvik edebileceği ileri sürülmektedir ${ }^{44}$.

FHA jel sisteminde, agaroz molekülleri dentin yüzeyinde pozitif yüklü kollajen moleküllerine bağlanarak çekirdeklenme bölgeleri oluştururken kalsiyum ve fosfat iyonları mineralleşmenin gerçekleştiği bu bölgelere dağılır. Atomik veya moleküler yapılar, enerji açıdan kendilerine uygun bölgeleri bularak olgunlaşmamış kristalin yüzeyine eklenirler. Yüzey kristallerle kaplandığında daha büyük kristaller bir araya toplanır ve düzgün bir yönde dururlar. Jel yapısı hidrojel bir mikro çevre sağlarken agarozun da remineralizasyon odaklarının oluşması ve büyümesinde indükleyici olarak rol aldığı düşünülmektedir ${ }^{11,27,44}$.

Wang ve arkadaşları ${ }^{27}$, indirekt pulpa kaplama materyali olarak FHA jel, kalsiyum hidroksit $\left(\mathrm{Ca}(\mathrm{OH})_{2}\right)$ ve mineral trioksit agregat (MTA) kullandıkları çalışmalarında lezyon yüzeyi altı mineral yoğunluğunda ve derinliğinde üç grupta da önemli bir değişikliğin olmadığını göstermişlerdir. Bu durumun ise dentin yüzeyinde oluşan apatitin, kollajen fibrilleri arasındaki boşluğa girmek için fazla büyük olması ile açıklanabileceğini bildirmişlerdir. FHA jelin, mineral alımını arttırarak lezyon yüzeyinde hipermineralizasyona neden olduğu bu nedenle de lezyonun derin kısımlarının etkili bir şekilde remineralize olamadığı gösterilmiştir. Çalışmanın sonuçlarına göre FHA jelinin, remineralize etme özelliği olan uygun bir indirekt pulpa kaplama malzemesi olarak kullanılabileceğini bildirmişlerdir.

\section{Nano Hidroksiapatit}

Nano boyutlardaki sentetik hidroksiapatit (nHap) parçacıkları; mine hidroksiapatitine morfolojik ve yapısal açısından benzerlik göstermektedir. n-HAp, biyouyumlu ve biyoaktif bir madde olarak kabul edilmektedir. Son yıllarda yapılan birçok çalışmada diş macunları ve ağız gargaralarına eklenen n-HAp' ın başlangıç çürük lezyonlarında remineralizasyon potansiyelinin olduğu gösterilmiştir ${ }^{45-48}$. Ancak; dentin çürükleri üzerine olan etkisi ile ilgili sınırlı sayıda çalışma mevcuttur $^{28}$.

Zandim ve arkadaşları ${ }^{28}$, in vitro ortamın sınırlamaları çerçevesinde nano hidroksiapatitli diş macunlarının, mine ve dentin lezyonlarında benzer remineralizasyon etkisi ortaya koyduğunu göstermişlerdir. Dentinde çinko karbonat ilave edilmiş ve edilmemiş n-HAp diş macunlarının, amin fluoridli diş macununa kıyasla daha yüksek remineralizasyon etkisi olduğunu ve diş bakım ürünlerindeki nano hidroksiapatitin biyoremineralizasyonu teşvike yardımcı olabileceğini bildirmişlerdir.

\section{Kalsiyum Fosfat}

Kalsiyum fosfat partikülleri, dentin ana inorganik bileşenlerinden biri olduğundan remineralizasyon 
için umut vadeden materyallerdendir ${ }^{29}$. Ticari olarak temin edilebilen saf kalsiyum fosfatların, partikül büyüklüklerine bağlı olarak lezyon içerisinde düşük aktivite ve penetrasyon göstermelerinden dolayı remineralizasyon çalışmalarında kullanımları uygun bulunmamaktadır. Bununla birlikte nano boyutlardaki kalsiyum fosfatların, demineralize dentinin organik matrisinin düzenlenmesi için mevcut yüzey alanını arttırdığı bildirilmiştir ${ }^{49}$.

\section{a. Nano - $\boldsymbol{\beta}$ - Trikalsiyum Fosfat}

Shibata ve arkadaşları ${ }^{25}$, yaptıkları in vitro çalışmada insan çürüklü daimi molar dişleri kolloidal hidroksiapatit ve $\beta$-trikalsiyum fosfat solüsyonlarına 10 gün maruz bırakılarak numunelerin mineral yoğunlukları ve mikro mekanik özellikleri değerlendirilmiştir. $\beta$-trikalsiyum fosfat içerisine daldırılmış numunelerde remineralizasyon sonrası dentin elastik modülü ve mineral yoğunluğunun hidroksiapatite daldırılmış olanlara göre daha fazla arttığı gösterilmiştir. Bununla birlikte; mineral yoğunluğundaki artışın mikro mekanik iyileşme ile orantılı olmamasından dolayı mineral yoğunluğunun tek başına mekanik özelliklerin göstergesi olmadığını bildirmişlerdir.

\section{b. Amorf Kalsiyum Fosfat (ACP)}

ACP, aşırı derecede doymuş kalsiyum fosfat solüsyonundan çökelen başlangıç katı fazdır. Mükemmel biyoaktivitesi, yüksek hücre adezyonu, sitotoksik olamaması ve osteokondüktif özelliklerinden dolayı diş hekimliği alanında kullanılmaktadır ${ }^{50,51}$. Oktakalsiyum fosfat veya apatitik ürünler gibi kararlı kristal fazlara kolayca dönüşebildiğinden biyomineralizasyonda apatit oluşumunda geçici bir faz gibi rol oynadığı düşünülmektedir ${ }^{52,53}$.

Ning ve arkadaşları ${ }^{11}$, yaptıkları in vitro çalışmada çürüksüz insan daimi üçüncü molar dişlerinden elde ettikleri dentin numunelerine demineralizasyon işlemi sonrasında 10 gün boyunca belirli aralıkla kalsiyum fosfat yüklü agaroz jel uygulanması sonucunda oluşan hidroksiapatit kristalleri ile dentin yüzeyinin tamamen kaplandığını ve tübüllerin tıkandığını göstermişlerdir.

\section{b.1. Kazein Fosfopeptid - Amorf Kalsiyum Fosfat (CPP-ACP)}

Kazein fosfopeptid - amorf kalsiyum fosfat (CPP-ACP) kompleksindeki kazein fosfopeptit, içerdiği fosfoserin uzantıları sayesinde amorf kalsiyum fosfatı stabilize ederek diş sert dokularının remineralizasyonu için gerekli olan kalsiyum ve fosfat iyonlarını sağlayabilmektedir ${ }^{23,54}$.

Cao ve arkadaşları ${ }^{30}$ tarafından yapılan in vitro bir çalışmada çürüksüz insan daimi üçüncü molar dişlerinden elde edilen dentin numuneleri demineralizasyon işlemi sonrası 10 gün boyunca CPP-ACP solüsyonunda bekletildikten sonra yapılan incelemelerde fosforile dentinin kollajen fibrillerinde hidroksiapatit kristallerinin oluşumu gösterilmiştir. Elde edilen veriler ışı̆ında, CPP-ACP uygulamasının biyomimetik remineralizasyonu indükleme potansiyeline sahip olduğu bildirilmiştir.

Rahiotis ve arkadaşları ${ }^{23}$ ise CPP-ACP uygulanmasının, sağlıklı dentin yüzeyinde demineralizasyonu engellediğini ve dentinde oluşturulan yapay çürük lezyonlarında ise remineralizasyonu arttırdığını göstermişlerdir. Dolayısıyla diş çürüklerinin önlenmesinde CPP-ACP uygulanmasını önerdiklerini bildirmişlerdir.

\section{b.2. Nanopartiküllü Amorf Kalsiyum Fosfat Kompozitler}

Kalsiyum fosfat dolduruculu kompozitler, kalsiyum ve fosfat iyonu salınımı yaparak diş çürüklerini remineralize edebilen materyallerdendir ${ }^{55,56}$. Geleneksel kalsiyum fosfat kompozitleri, 1-55 um 'lik kalsiyum fosfat parçacıkları bulundurmakla birlikte düşük mekanik özelliklere sahiptirler. Son zamanlarda ortalama boyutları $116 \mathrm{~nm}$ olan amorf kalsiyum fosfat nanopartikülleri sentezlenmiştir. Nanopartiküllü amorf kalsiyum fosfat kompozitlerin, kalsiyum ve fosfat iyonlarını yüksek seviyelerde serbest bırakırken mekanik özelliklerinin geleneksel kalsiyum fosfat kompozitlerden iki kat daha fazla olduğu bildirilmiştir ${ }^{57,58}$.

Yapılan in vitro bir çalışmada, çürüksüz insan daimi molar dişlerinden elde edilen dentin numuneleri demineralizasyon işlemi sonrasında nanopartiküllü amorf kalsiyum fosfat kompozitin tek başına ve biyomimetik analogla birlikte kullanılacak şekilde kaplanmıştır. Bu işlem sonrasında numuneler, yapay tükürük ve laktik asit uygulamalarını içeren 21 günlük bir siklusa tabi tutulmuştur. Uygulanan farklı tedaviler sonucunda nanopartiküllü amorf kalsiyum fosfat kompozitin demineralize dentin numulerinde kalsiyum ve fosfat iyon konsantrasyonunu büyük oranda arttırdığı ve ortamdaki asidi nötralize ederek dentin remineralizasyonunu teşvik ettiği gösterilmiştir. Ayrıca bu kompozitlerin biyomimetik analogla birlikte kullanımlarının demineralize dentinin remineralizasyonunu ve sertliğini daha fazla arttırdığı bildirilmiştir ${ }^{31}$.

\section{Kalsiyum Silikat}

Geleneksel olarak mineral trioksit agregat (MTA) olarak adlandırılan kalsiyum silikat çimentoları $\left(\mathrm{Ca}_{2} \mathrm{SiO}_{4}\right)$; Portland türevi çimentolardır ${ }^{59}$. Nemi tolere edebilen, biyolojik sıvılar varlığında polimerize olarak sertleşebilen hidrofilik malzemelerdir. Kalsiyum silikat 
çimentolar, kısa bir indüksiyon periyodunda kalsiyum ve hidroksil iyonlarını çevresindeki sıvılar içine salarak apatit içeren dokuların oluşumunu teşvik eden biyoaktif davranışa sahip materyallerdir ${ }^{60-62}$. Yapılan çalışmalarda biyouyumluluk ve biyoaktivite özellikleri klinik olarak gösterilmiştir $32,61,63,64$. Bütün bu özelliklerinden dolayı kalsiyum silikat içeren materyallerin demineralize dentinin remineralizasyonunda kullanılabileceği bildirilmiştir ${ }^{32,33}$

Gandolfi ve arkadaşları $^{32}$ tarafından yapılan çalışmada kalsiyum silikat tozu içeren kompozitlerin yedi günde demineralize dentin yüzeyinde karbonatlı apatite benzer bir yapının oluşumunu teşvik ettiği gösterilmiştir. Başka bir çalışmada ise MTA' nın dentin çürüğündeki remineralizasyon etkinliği, poliakrilik asit ve sodyum trimetafosfat gibi matriks proteinlerinin biyomimetik analogları eklenmiş olan simüle vücut SIVISI (SBF) içinde incelenmiştir. MTA'nın dentin remineralizasyon etkinliğinin biyomimetik analoglarla birlikte kullanımında artmış olduğu gösterilmiştir ${ }^{33}$.

\section{Fonksiyonel Biyomimetik Analoglar}

Yakın zamanda, yüksek bir pH ile kalsiyum ve fosfat iyonu salınımı yapabilen nanoteknoloji ürünü olan fonksiyonel biyomimetik analoglar geliştirilmiştir. $\mathrm{Bu}$ analoglar, doğal dentin mineralizasyonu ile ilişkili kollajen olmayan proteinlerin yapısal özelliklerini taklit etmektedirler ${ }^{35}$. Biyomimetik analoglar, çekirdeklenmenin başlaması için gerekli olan nano öncüleri salıvermek ve yapıyı stabilize edebilmek için dentin matriks proteinlerini taklit eden iki polianyonik analogu kullanmaktadırlar. Böylece, intrafibriller apatit kristallerinin oluşumuna rehberlik eden moleküller gibi davranmaktadır $^{44}$. Biyomimetik analogların, dentin adeziv sistemlerinde fosforik asit kullanılarak oluşturulan bozulmuş ve su geçirgenliği artmış olan rezin - dentin ara yüzeyinde kollajen matrikslerinin remineralizasyonu için kullanılabileceği bildirilmiştir ${ }^{65-67}$.

Yapılmış olan in vitro bir çalışmada, biyomimetik analogların herhangi bir remineralizasyon ortamının yokluğunda tamamen demineralize dentinin remineralizasyonunu gerçekleştiremediği buna karşın remineralizasyon ortamının varlığında kollajen matriksinde intrafibriller remineralizasyonun meydana geldiği tespit edilmiştir ${ }^{68}$.

Son yıllarda biyoremineralizasyonda kullanılan fonksiyonel biyomimetik analoglar ve görevleri ${ }^{34}$ :

\section{a. Poliakrilik asit (PAA)}

Biyomimetik remineralizasyondaki görevleri arasında $33,35,36,69$;

- $\quad$ ACP 'nin stabilize ederek ömrünün uzatılması,
- Dentin Matriks Proteini - 1 (DMP-1) 'in kalsiyum fosfat bağlanma yerlerinin taklit edilmesi bulunmaktadır.

\section{b. Polivinilfosfonik asit (PVPA)}

Biyomimetik remineralizasyondaki görevleri arasında ${ }^{37,69}$;

- DMP' lerin analoglarının oluşturulması,

- Matriks metalloproteinazların aktivitesini inhibe edilmesi,

- ACP nano öncüllerinin kollajen matriksine dâhil edilmesi

- DMP-1' in kollajene bağlamasının sağlanması bulunmaktadır.

Tay ve arkadaşlarının ${ }^{35}$, yaptıkları in vitro çalışmada çürüksüz insan daimi üçüncü molar dişlerinden elde edilen dentin numuneleri demineralizasyon işlemi sonrasında MTA, PAA ve PVPA' dan oluşan solüsyonda bekletilerek $2,4,6$ ve 8 . haftalarda incelemeler yapılmıştır. Demineralize dentinde, intrafibriller mineral oluşumunun ilk olarak 2 hafta kadar kısa bir süre görüldüğü ve 8 . haftanın sonunda maksimum remineralizasyonun sağlandığı bildirilmiştir. Ayrıca, remineralize kollajen matriksinde yeni oluşan apatit kristallerinin boyut ve sıralanmasının doğal dentindeki kristallere yakın olduğu gösterilmiştir.

\section{c. Sodyum trimetafosfat (STMP) $\left(\mathrm{Na}_{3} \mathrm{P}_{3} \mathrm{O}_{9}\right)$}

Biyomimetik remineralizasyondaki görevleri arasında ${ }^{30,33,36,39}$;

- Tip I kollajenin fosforile edilmesi,

- Demineralize kollajen matriksine bağlanılması,

- ACP nano öncüllerinin remineralizasyon alanına toplanmasının sağlaması bulunmaktadır.

Yapılmış olan in vitro bir çalışmada, çürüksüz insan daimi üçüncü molar dişlerinden elde edilen dentin numuneleri demineralizasyon işlemi sonrasında MTA ve STMP 'den oluşan solüsyonda bekletilerek 1, 2,3 ve 4 . ay sonunda ölçümler yapılmıştır. 4 ay sonunda STMP uygulanan numunelerde kontrol grubuna göre mineral konsantrasyon artışının ve lezyon derinliğindeki azalmanın en fazla olduğu gösterilmiştir ${ }^{38}$.

\section{d. Poliamido amin (PAMAM)}

Poliamido amin; iyi tanımlanmış boyut ve şeklinin yanı sıra fazla sayıdaki reaktif grupları ile karakterize dallı bir polimerdir. Son yıllarda, diş dokularının remineralizasyonunu sağlamak için çeşitli PAMAM dendrimer türleri kullanılmaya başlanılmıştır ${ }^{40,70}$. Amin terminalli PAMAM'in (PAMAM- $\mathrm{NH}_{2}$ ) dentin kollajen fibrillerinin yüzeyindeki remineralizasyonda etkili olduğu, orta derecede remineralizasyon yeteneğine sahip olan polihidroksi terminalli PAMAM'in (PAMAM- 
$\mathrm{OH})$ dentin tübül tıkanmasını indüklediği, karboksi terminalli PAMAM'in (PAMAM-COOH) ise kollajen fibriller içerisine kalsiyum ve fosfat iyonlarının alınımını arttırdığı bildirilmiştir ${ }^{71}$. Yapılan bir hayvan çalışmasında fosfat terminalli PAMAM' in (PAMAM- $\mathrm{PO}_{3} \mathrm{H}_{2}$ ) ise dentini başarıyla remineralize ettiği gösterilmiştir ${ }^{40,72}$.

Sonuç olarak PAMAM'in dentinin biyomimetik remineralizasyonunda, kollajen fibrillerine bağlanma ve ACP nano öncüllerinin kollajen matrikse dâhil edilmesi gibi görevleri bulunmaktadır ${ }^{34}$.

Liang ve arkadaşlarının ${ }^{31}$ yaptıkları in vitro çalışmada; çürüksüz insan daimi molar dişlerinden elde edilen dentin numunelerine demineralizasyon işlemi sonrasında PAMAM, nanopartiküllü amorf kalsiyum fosfat kompozit ve PAMAM - nanopartiküllü amorf kalsiyum fosfat kompozitin birlikte kullanıldığı üç farklı tedavi yöntemi uygulanmıştır. Tüm numuneler, yapay tükürük ve laktik asit uygulamalarını içeren 21 günlük bir siklusa tabi tutulmuştur.

Üç gruba ayrılan demineralize dentin numulerinde uygulanan farklı tedavilerin remineralizasyonu üzerine etkilerini araştırmışlardır.

Çalışma sonucunda ise;

(1) PAMAM tedavisinin demineralize dentini önemli ölçüde remineralize ettiği,

(2) Nanopartiküllü amorf kalsiyum fosfat kompozitin, demineralize dentin numunelerinde kalsiyum fosfat iyon konsantrasyonunu büyük oranda arttırdığı ve ortamdaki asidi nötralize ederek dentin remineralizasyonunu teşvik ettiği,

(3) Demineralize dentin numunelerinde PAMAM ve nanopartiküllü amorf kalsiyum fosfat kompozitin birlikte kullanımlarının tek başına kullanımlarına göre remineralizasyonu ve sertliği daha fazla arttırdığı bildirilmiştir.

\section{e. Agaroz Hidrojel}

Agaroz, tekrarlayan monomer birimleri içeren polianyonik bir polisakkarittir. Agarozun anyonik grupları, kollajenin pozitif yüklü moleküllerine bağlanarak hidroksiapatit kristallerinin büyümesini sağlamaktadır. Ayrıca, yönlendirilmiş iyon difüzyonu aracılığı ile kalsiyum-fosfat iyonlarının dentin yüzeyine taşınmasını ve hidroksiapatit kristallerinin oluşmasını kolaylaştırmaktadır ${ }^{11}$

Ning ve arkadaşlarının ${ }^{11}$ yaptıkları çalışmada, biyomimetik remineralizasyonu sağlamak için fosfat iyonu - kalsiyum klorür solüsyonu içeren agaroz jel kullanılmıştır. Bu hidrojel yapının, demineralize dentin yüzeyinde hidroksiapatit birikimini sağlayabildiği ve artan remineralizasyon zamanı ile doğru orantılı olarak dağılan hidroksiapatitlerin dentin yüzeyini tamamen örterek tübülleri tıkadığı gösterilmiştir.

Yapılmış olan diğer çalışmalarda da agaroz jel sisteminin; açık dentin tübüllerini tıkadığı ve remineralize dentin yüzeyini mine benzeri bir dokuyla kaplandığı gösterilmiştir. Böylelikle dentinin mikro yapısının yeniden oluşturabileceği bildirilmiştir ${ }^{8,9}$.Bu çalışmaların sonuçlarına göre agaroz hidrojel sisteminin, dentin çürüğü ve aşırı duyarlıı̆ııın tedavisinde yeni yöntemlerin geliştirilmesine katkıda bulunabileceği bildirilmiştir.

\section{f. L-Glutamik Asit ( L- Glu )}

L-glutamik asidin dentinin biyomimetik remineralizasyonunda; remineralizasyonun başlaması ve teşvik edilmesi, DMP-1 'in glutamik asit bakımından zengin alanlarıyla yer değiştirme gibi fonksiyonları bulunmaktadır $^{34}$. Yapılan bir çalışmada, kalsiyumu azaltılmış dentin kollajeninin remineralizasyonu için poliakrilik asit ve L-glutamik asit içeren biyomimetik bir solüsyon kullanılmıştır. Poliakrilik asit ve L-glutamik asidin kooperatif etkisi ile iki günün sonunda elde edilen remineralize dentin tabakasının doğal dentin ile aynı özelliklere sahip olduğu bildirilmiştir ${ }^{41}$.

\section{g. Dentin Matriks Proteini - 1 (DMP -1)} türevi sentetik oligopeptitler

DMP-1, dentin matriksinde biyomineralizasyonu büyük ölçüde düzenleyen kollajen olmayan bir proteindir $^{73}$. Remineralizasyon için gerekli olan öncü yapıları oluşturarak ortamdaki kalsiyum - fosfat iyonlarının stabilize etmektedir ${ }^{74}$. Ayrıca, ACP nanopartiküllerinin kollajenin intrafibriller bölgesine yerleşmesini sağlayarak bu bölgede apatit kristallerini oluşturmaktadır ${ }^{75}$. İntrafibriller boşluk bölgelerinde kristal büyümesi, dentinin mekanik özelliklerinin artmasını ve kollajenin enzimatik-asidik değişimlerden korunmasını sağlamaktadır ${ }^{14}$.

Padovano ve arkadaşlarının ${ }^{42}$ yaptıkları in vitro çalışmada, DMP-1' den türetilen sentetik oligopeptitin, remineralizasyon için gerekli öncü yapılarla kalsiyum fosfat iyonlarını stabilize ettiği ve kollajenaz ile muamele edilmiş dentin numunelerinde tip I kollajene bağlanarak hidroksiapatit oluşumunu desteklediği gösterilmiştir.

\section{h. Fosforilize Kitozan (P-chi)}

Dentinin biyomimetik remineralizasyonunda kullanılan fosforillenmiş kitozanın; remineralizasyonun başlatılması ve kollajen fibrillerine bağlanıp üzerindeki fonksiyonel grupların tanıtılması gibi görevleri bulunmaktadır ${ }^{34,76}$.

Neoh ve arkadaşları ${ }^{4}$ yapmış oldukları çalışmada, kısmen demineralize olmuş dentin yüzeyinde fluor 
ve $\mathrm{P}$ - chi' nin remineralizasyon etkileri karşılaştırılmıştır. Çalışmanın sonuçlarına göre demineralize dentinde kalan mineral miktarı az olduğunda fluorun remineralizasyon etkisinin sınırlı olduğunu buna karşın P-chi' nin yüzeye kalsiyum - fosfat iyonlarının çökelmesini önemli ölçüde indükleyebildiği gösterilmiştir. P- chi' nin, dentinin yüzeyel remineralizasyonunu kolaylaştırması nedeniyle dentin çürüğü ve hassasiyetinin tedavisinde kullanılabileceği bildirilmiştir.

\section{Biyoaktif Cam}

Biyoaktif camdan ayrılan iyonların, kollajen ile bağlanarak karbonatlanmış kalsiyumu eksik hidroksiapatit oluşturduğu ve bununla birlikte büyüme faktörü kodlayan genleri düzenleyerek osteojenik hücreleri matriks salgılamaya teşvik ettiği bildirilmiştir. Bu özelliklerinden dolayı biyoaktif cam, biyoaktivitesi yüksek bir materyal olarak kabul görmektedir ${ }^{77}$.

Fernando ve arkadaşları ${ }^{78}$ yaptıkları literatür taramasında, yapılmış olan çalışmalarda biyoaktif cam ile tedavi edilen demineralize dentin numunelerinde apatit oluşumunun teşvik edildiğini ancak remineralize edilen dentin numunelerinde mekanik özelliklerin değerlendirilmemesinden dolayı biyoaktif camın etkili bir remineralizasyon materyali olduğuna dair yeterli delil olmadığını bildirmişlerdir.

Vollenweider ve arkadaşları ${ }^{10}$ ise yapmış oldukları çalışmada, yapay çürük lezyonu oluşturulmuş dentin numunelerinin nanopartiküllü biyoaktif cam ile tedavisinden sonra mineral konsantrasyonunun arttığı ancak mekanik özelliklerinin ise doğal dentine göre çok daha düşük seviyede olduğunu göstermişlerdir. Bu durumun, demineralize dentin matriksinde kazanılan mineraller ile kollajen fibrilleri arasındaki eksik düzenlenmenin sonucunda oluşabileceği öne sürülmüştür.

Diş macunları, cam iyonomer siman ve dental kompozitler gibi materyallerde dolgu maddesi olarak biyoaktif camın kullanılması ile açığa çıkmış olan dentin tübüllerinin tıkanması, dentin ara yüzünde bağlantının geliştirilmesi ve mineral kaybı bulunan dentinin remineralizasyon yoluyla onarılması için araştırmalar devam etmektedir. Yapılan çalışmalarda dentin remineralizasyonu için biyoaktif camların etkinliği gösterilmiştir ${ }^{79-82}$.

\section{7. Çinko Klorid ve Çinko Oksit}

Osorio ve arkadaşları ${ }^{43}$ yaptıkları çalışmada, çinkonun demineralize dentinin tamir yeteneğini artırıp artırmadığını araştırmışlardır. Demineralize dentin numunelerinde, çinko klorid ve çinko oksit solüsyonlarında depolandıktan sonra yapılan ölçümlerde mikro sertliğin arttığı ve hidroksiapatit oluşumunun gözlendiği bildirilmiştir. Çinko içeren çözeltilerde depolanan dentinde scholzite (hidratlı kalsiyum çinko fosfat) oluşumu ile karşılaştıklarını ve çinkonun dentin demineralizasyon - remineralizasyon işlemleri arasındaki dengeye olumlu etkileri olduğunu bildirmişlerdir.

\section{SONUÇ}

Demineralizasyon ve/veya çürük durumlarında dentinin remineralizasyonu mineye göre çok daha karmaşık bir süreç hâlini almaktadır. Aslında mine ve dentin arasındaki morfolojik farklılıklar, yapıların ideal remineralizasyonundan beklenen sonuçların aynı olmamasına neden olmaktadır. Bu nedenle, dentinin remineralizasyonunda kullanılabilecek farklı yöntem ve materyaller günümüzde hâlen araştırımaktadır.

Yapılmış olan araştırmalarda, demineralize dentinin remineralizasyonu sonrası kazandığı minerallerin yanı sıra fizyolojik hidrasyon koşullarında yük altındaki mekanik özelliklerinin de incelenmesi gerektiği ve yalnızca mineral kazancının sağlanmış olmasının etkili remineralizasyonun sağlandığı anlamına gelmediği bildirilmiştir. Ancak konuyla ilgili çoğu çalışmada değerlendirilme kriteri olarak sadece demineralize dentinin remineralizasyonu sonucunda elde edilen mineral kazancı dikkate alınmıştır. Dolayısıyla mevcut literatürdeki eksikliğin giderilmesi adına demineralize dentinin remineralizasyonu sonrasında dokunun mineral yoğunluğuna ek olarak mekanik özelliklerindeki iyileşmenin de değerlendirildiği daha kapsamlı çalışmalara intiyaç vardır ${ }^{3,23,28,32,83}$.

Yapılan bu derlemede, son yılların güncel konulardan biri olan dentinin biyomimetik remineralizasyon mekanizmasından bahsedilerek konuyla ilgili yeni kullanıma giren ve umut vaad eden materyaller üzerinde durulmuştur. Araştırmamızın bu özeliklerinden dolayı dentinin biyomimetik remineralizasyonu ile ilgili ileride yapılacak olan çalışmalar için araştırmacılara yol gösterici nitelikte olacağı kanaatindeyiz.

Bu çalışma, çalışmayı yürüten tüm yazarlar tarafından okunmuş ve onaylanmış orijinal bir çalışmadır. Herhangi bir yazar, kurum ya da kuruluş ile çıkar çatışması olmadığını belirtilmek isteriz.

\section{KAYNAKLAR}

1. Ekiz E, Odabaş ME. Başlangıç lezyonlarının tedavisinde rezin infiltrasyon tekniğinin etkinliğinin değerlendirilmesi. Atatürk Üniv Diş Hek Fak Derg 2015; 12: 86-91 
2. Uzer Çelik E, Yazkan B, Katırcı G. Başlangıç çürük lezyonlarının tedavisi. Atatürk Üniv Diş Hek Fak Derg 2011; 21: 48-56

3. Bertassoni LE, Habelitz S, Kinney JH, Marshall SJ, Marshall GW Jr. Biomechanical perspective on the remineralization of dentin. Caries Res 2009;43: 707.

4. Xu Z, Neoh KG, Lin CC, Kishen A. Biomimetic deposition of calcium phosphate minerals on the surface of partially demineralized dentine modified with phosphorylated chitosan. J Biomed Mater Res B Appl Biomater 2011;98: 150-9.

5. Marshall GW Jr, Inai N, Wu-Magidi IC, Balooch M, Kinney J H, Tagami J, Marshall SJ. Dentin demineralization: effects of dentin depth, $\mathrm{pH}$ and different acids. Dent Mater 1997; 13: 338-43.

6. Thompson V, Craig RG, Curro FA, Green WS, Ship JA. Treatment of deep carious lesions by complete excavation or partial removal: a critical review. J Am Dent Assoc 2008; 139: 705-12.

7. Mattos J, Soares GM, Ribeiro Ade A. Current status of conservative treatment of deep carious lesions. Dent Update 2014; 41: 452-4, 456.

8. Han M, Li QL, Cao Y, Fang H, Xia R, Zhang ZH. In vivo remineralization of dentin using an agarose hydrogel biomimetic mineralization system. Sci Rep 2017; 7: 41955.

9. Wu XT, Cao Y, Mei ML, Chen JL, Li QL, Chu CH. An electrophoresis-aided biomineralization system for regenerating dentin- and enamel-like microstructures for the self-healing of tooth defects. Cryst Growth Des 2014; 14: 5537-48.

10. Vollenweider M, Brunner TJ, Knecht S, Grass RN, Zehnder M, Imfeld T, Stark WJ. Remineralization of human dentin using ultrafine bioactive glass particles. Acta Biomater 2007; 3: 936-43.

11. Ning TY, Xu XH, Zhu LF, Zhu XP, Chu CH, Liu LK, Li QL. Biomimetic mineralization of dentin induced by agarose gel loaded with calcium phosphate. J Biomed Mater Res B Appl Biomater 2012; 100: 138-44.

12. Mai S, Kim YK, Toledano M, Breschi L, Ling JQ, Pashley DH, Tay FR. Phosphoric acid esters cannot replace polyvinylphosphonic acid as phosphoprotein analogs in biomimetic remineralization of resin-bonded dentin. Dent Mater 2009; 25: 1230-9.

13. Marshall GW Jr, Marshall SJ, Kinney JH, Balooch M. The dentin substrate: structure and properties related to bonding. J Dent 1997; 25: 441-58.
14. Balooch M, Habelitz S, Kinney JH, Marshall SJ, Marshall GW. Mechanical properties of mineralized collagen fibrils as influenced by demineralization. J Struct Biol 2008; 162: 404-10.

15. Jager I, Fratzl P. Mineralized collagen fibrils: a mechanical model with a staggered arrangement of mineral particles. Biophys J 2000; 79: 1737-46.

16. Kinney JH, Habelitz S, Marshall SJ, Marshall GW. The importance of intrafibrillar mineralization of collagen on the mechanical properties of dentin. J Dent Res 2003; 82: 957-961.

17. Kinney JH, Marshall SJ, Marshall GW. The mechanical properties of human dentin: a critical review and re-evaluation of the dental literature. Crit Rev Oral Biol Med 2003; 14: 13-29.

18. Angker L, Nijhof N, Swain MV, Kilpatrick NM. Influence of hydration and mechanical characterization of carious primary dentine using an ultra-micro indentation system (UMIS). Eur J Oral Sci 2004;112: 231-6.

19. Oyen ML. Nanoindentation hardness of mineralized tissues. J Biomech 2006; 39: 2699-702.

20. Mahoney E, Holt A, Swain M, Kilpatrick N. The hardness and modulus of elasticity of primary molar teeth: an ultra-micro-indentation study. J Dent 2000; 28: 589-94.

21. Weiner $S$, Traub W. Bone structure: from angstroms to microns. FASEB J 1992; 6: 879-85.

22. Zaura E, Buijs MJ, Ten Cate JM. Effects of ozone and sodium hypochlorite on caries-like lesions in dentin. Caries Res 2007; 41: 489-92.

23. Rahiotis C, Vougiouklakis G. Effect of a CPP-ACP agent on the demineralization and remineralization of dentine in vitro. J Dent 2007; 35: 695-8.

24. Hara AT, Karlinsey RL, Zero DT. Dentine remineralization by simulated saliva formulations with different $\mathrm{Ca}$ and Pi contents. Caries Res 2008; 42: 51-6.

25. Shibata Y, He LH, Kataoka Y, Miyazaki T, Swain MV. Micromechanical property recovery of human carious dentin achieved with colloidal nano-betatricalcium phosphate. J Dent Res 2008; 87: 233-7.

26. Bertassoni LE, Habelitz S, Pugach M, Soares, PC, Marshall SJ, Marshall GW Jr. Evaluation of surface structural and mechanical changes following remineralization of dentin. Scanning 2010; 32: 312-9. 
27. Qianqian Wang, Shize Liu, Xuejun Gao, et al., "Remineralizing Efficacy of Fluorohydroxyapatite Gel on Artificial Dentinal Caries Lesion," Journal of Nanomaterials, vol. 2015, Article ID 380326, 9 pages, 2015. doi:10.1155/2015/380326

28. Tschoppe P, Zandim DL, Martus P, Kielbassa, AM. Enamel and dentine remineralization by nanohydroxyapatite toothpastes. J Dent 2011; 39: 4307.

29. Perkin KK, Turner JL, Wooley KL, Mann S. Fabrication of hybrid nanocapsules by calcium phosphate mineralization of shell cross-linked polymer micelles and nanocages. Nano Lett 2005; 5: 1457-61.

30. Cao Y, Mei ML, Xu J, Lo EC, Li Q, Chu CH. Biomimetic mineralisation of phosphorylated dentine by CPP-ACP. J Dent 2013; 41: 818-25.

31. Liang K, Weir MD, Xie X, Wang L, Reynolds MA, Li J, $\mathrm{Xu} \mathrm{HH}$. Dentin remineralization in acid challenge environment via PAMAM and calcium phosphate composite. Dent Mater 2016; 32: 1429-40.

32. Gandolfi MG, Taddei P, Siboni F, Modena E, De Stefano ED, Prati C. Biomimetic remineralization of human dentin using promising innovative calciumsilicate hybrid "smart" materials. Dent Mater 2011; 27: 1055-69.

33. Qi YP, Li N, Niu LN, Primus CM, Ling JQ, Pashley $\mathrm{DH}$, Tay FR. Remineralization of artificial dentinal caries lesions by biomimetically modified mineral trioxide aggregate. Acta Biomater 2012; 8: 836-42.

34. Cao CY, Mei ML, Li QL, Lo EC, Chu CH. Methods for biomimetic remineralization of human dentine: a systematic review. Int J Mol Sci 2015; 16: 461527.

35. Tay FR, Pashley DH. Guided tissue remineralisation of partially demineralised human dentine. Biomaterials 2008; 29: 1127-37.

36. Gu L, Kim YK, Liu Y, Ryou H, Wimmer CE, Dai L, Arola DD, Looney SW, Pashley DH, Tay FR. Biomimetic analogs for collagen biomineralization. J Dent Res 2011; 90: 82-7.

37. Liu Y, Mai S, Li N, Yiu CKY, Mao J, Pashley DH, Tay FR. Differences between top-down and bottom-up approaches in mineralizing thick, partially demineralized collagen scaffolds. Acta Biomater 2011; 7: 1742-51.
38. Liu Y, Li N, Qi Y, Niu L, Elshafiy S, Mao J, Breschi L, Pashley D, Tay F. The use of sodium trimetaphosphate as a biomimetic analog of matrix phosphoproteins for remineralization of artificial caries-like dentin. Dent Mater 2011; 27: 465-77.

39. Zhang $X$, Neoh KG, Lin CC, Kishen A. Remineralization of partially demineralized dentine substrate based on a biomimetic strategy. J Mater Sci Mater Med 2012; 23: 733-42.

40. Li J, Yang J, Li J, Chen L, Liang K, Wu W, Chen X, $\mathrm{Li}$ J. Bioinspired intrafibrillar mineralization of human dentine by PAMAM dendrimer. Biomaterials 2013; 34: 6738- 47.

41. Sun JC, Chen CQ, Pan HH, Chen Y, Mao CY, Wang W, Tang RK, Gu XH. Biomimetic promotion of dentin remineralization using L-glutamic acid: Inspiration from biomineralization proteins. J Mater Chem B 2014; 2: 4544-53.

42. Padovano JD, Ravindran $S$, Snee PT, Ramachandran A, Bedran-Russo AK, George A. DMP1-derived peptides promote remineralization of human dentin. J Dent Res 2015; 94: 608-14.

43. Osorio R, Osorio $E$, Cabello I, Toledano M. Zinc induces apatite and scholzite formation during dentin remineralization. Caries Res 2014; 48: 27690.

44. Gower LB. Biomimetic model systems for investigating the amorphous precursor pathway and its role in biomineralization. Chem Rev 2008; 108: 4551-627.

45. Yamagishi K, Onuma K, Suzuki T, Okada F, Tagami J, Otsuki M, Senawangse P. Materials chemistry: a synthetic enamel for rapid tooth repair. Nature 2005; 433: 819.

46. Roveri N, Foresti E, Lelli M, Lesci IG. Recent advances in preventing teeth health hazard: The daily use of hydroxyapatite instead of fluoride. Recent Pat Biomed Eng 2009; 2: 197-215.

47. Huang SB, Gao SS, Yu HY. Effect of nanohydroxyapatite concentration on remineralization of initial enamel lesion in vitro. Biomed Mater 2009; 4: 034104 doi: 10.1088/1748$6041 / 4 / 3 / 034104$.

48. Fujisawa R, Kuboki Y, Sasaki S. Changes in interaction of bovine dentin phosphophoryn with calcium and hydroxyapatite by chemical modifications. Calcif Tissue Int 1986; 39: 248-51. 
49. Shibata Y, Yamamoto H, Miyazaki T. Colloidal betatricalcium phosphate prepared by discharge in a modified body fluid facilitates synthesis of collagen composites. J Dent Res 2005; 84: 827-31.

50. Dorozhkin SV. Calcium orthophosphates as bioceramics: state of the art. J Funct Biomater 2010; 1: 22-107.

51. Zhao J, Liu Y, Sun WB, Zhang H. Amorphous calcium phosphate and its application in dentistry. Chem Cent J 2011; 5: 40.

52. Boskey AL. Amorphous calcium phosphate: the contention of bone. J Dent Res 1997; 76: 1433-6.

53. Wang L, Nancollas GH. Dynamics of Biomineralization and Biodemineralization. Met Ions Life Sci 2010; 4: 413-56.

54. Keskin G, Güler Ç. Diş Hekimliğinde Kazein Fosfopeptit Amorf Kalsiyum Fosfat: Bir Literatür Derlemesi. Atatürk Üniv. Diş Hek. Fak. Derg. 2013; 23: 261-8.

55. Langhorst SE, O'Donnell JN, Skrtic D. In vitro remineralization of enamel by polymeric amorphous calcium phosphate composite: quantitative microradiographic study. Dent Mater 2009; 25: 884-91.

56. Dickens SH, Flaim GM, Takagi S. Mechanical properties and biochemical activity of remineralizing resin-based Ca-PO4 cements. Dent Mater 2003; 19: 558-66.

57. $\mathrm{Xu} \mathrm{HH}$, Moreau JL, Sun L, Chow LC. Nanocomposite containing amorphous calcium phosphate nanoparticles for caries inhibition. Dent Mater 2011; 27: 762-9.

58. Moreau JL, Sun L, Chow LC, Xu HH. Mechanical and acid neutralizing properties and bacteria inhibition of amorphous calcium phosphate dental nanocomposite. J Biomed Mater Res B Appl Biomater 2011; 98: 80-8.

59. Şen Tunç E, Çetinkaya S. Mineral trioxide aggregate: Literatür derlemesi. Atatürk Üniv. Diş Hek. Fak. Derg. 2006; 16: 46-53.

60. Parirokh M, Torabinejad M. Mineral trioxide aggregate: a comprehensive literature review--Part III: Clinical applications, drawbacks, and mechanism of action. J Endod 2010; 36: 400-13.

61. Gandolfi MG, Taddei P, Tinti A, De Stefano Dorigo E, Rossi PL, Prati C. Kinetics of apatite formation on a calcium-silicate cement for root-end filling during ageing in physiological-like phosphate solutions. Clin Oral Investig 2010; 14: 659-68.
62. Sarkar NK, Caicedo R, Ritwik P, Moiseyeva R, Kawashima I. Physicochemical basis of the biologic properties of mineral trioxide aggregate. J Endod 2005; 31: 97-100.

63. Parirokh M, Torabinejad M. Mineral trioxide aggregate: a comprehensive literature review--Part I: chemical, physical, and antibacterial properties. J Endod 2010; 36: 16-27.

64. Torabinejad $M$, Parirokh $M$. Mineral trioxide aggregate: a comprehensive literature review--part II: leakage and biocompatibility investigations. J Endod 2010; 36: 190-202.

65. Tsuji T, Onuma K, Yamamoto A, Iijima M, Shiba K. Direct transformation from amorphous to crystalline calcium phosphate facilitated by motifprogrammed artificial proteins. Proc Natl Acad Sci USA 2008; 105: 16866-70.

66. Wong, T.S., B. Brough, and C.M. Ho, Creation of functional micro/nano systems through top-down and bottom-up approaches. Mol Cell Biomech, 2009. 6: p. 1-55.

67. Tay FR, Pashley DH. Biomimetic remineralization of resin-bonded acid-etched dentin. J Dent Res 2009; 88: 719-24.

68. Kim J, Arola DD, Gu L, Kim YK, Mai S, Liu Y, Pashley DH, Tay FR. Functional biomimetic analogs help remineralize apatite-depleted demineralized resin-infiltrated dentin via a bottom-up approach. Acta Biomater 2010; 6: 2740-50.

69. Gu LS, Kim YK, Liu Y, Takahashi K, Arun S, Wimmer CE, Osorio R, Ling JQ, Looney SW, Pashley DH, Tay FR. Immobilization of a phosphonated analog of matrix phosphoproteins within cross-linked collagen as a templating mechanism for biomimetic mineralization. Acta Biomater 2011; 7: 268-77.

70. Jia R, Lu Y, Yang CW, Luo X, Han Y. Effect of generation 4.0 polyamidoamine dendrimer on the mineralization of demineralized dentinal tubules in vitro. Arch Oral Biol 2014; 59: 1085-93.

71. Zhou Y, Yang J, Lin Z, Li J, Liang K, Yuan H, Li S, $\mathrm{Li}$ J. Triclosan-loaded poly(amido amine) dendrimer for simultaneous treatment and remineralization of human dentine. Colloids Surf B Biointerfaces 2014; 115: 237-43.

72. Zhang H, Yang J, Liang K, Li J, He L, Yang X, Peng $S$, Chen $X$, Ding $C$, Li J. Effective dentin restorative material based on phosphate-terminated dendrimer as artificial protein. Colloids Surf B 2015;128: 304-14. 
73. Tartaix PH, Doulaverakis M, George A, Fisher LW, Butler WT, Qin C, Salih E, Tan M, Fujimoto Y, Spevak $L$, Boskey AL. In vitro effects of dentin matrix protein-1 on hydroxyapatite formation provide insights into in vivo functions. J Biol Chem 2004; 279: 18115-20.

74. Nijhuis AW, Nejadnik MR, Nudelman F, Walboomers XF, te Riet J, Habibovic P, Tahmasebi Birgani Z, Li Y, Bomans PH, Jansen JA, Sommerdijk NA, Leeuwenburgh SC. Enzymatic pH control for biomimetic deposition of calcium phosphate coatings. Acta Biomater 2014; 10: 931-9.

75. Cao Y, Liu W, Ning T, Mei ML, Li QL, Lo EC, Chu $\mathrm{CH}$. A novel oligopeptide simulating dentine matrix protein 1 for biomimetic mineralization of dentine. Clin Oral Investig 2014; 18: 873-81.

76. Oyar P. Diş hekimliğinde kitin ve kitozan. Atatürk Üniv. Diş Hek. Fak. Derg. 2016; 26: 197-202.

77. Jones J.R. Review of bioactive glass: from Hench to hybrids. Acta Biomater 2013; 9: 4457-86.

78. Fernando D, Attik N, Pradelle-Plasse N, Jackson P, Grosgogeat B, Colon P. Bioactive glass for dentin remineralization: A systematic review. Mater Sci Eng C 2017; 76: 1369-77.

79. Taubock TT, Zehnder M, Schweizer T, Stark WJ, Attin T,Mohn D. Functionalizing a dentin bonding resin to become bioactive. Dent Mater 2014; 30: 868-75.

80. Chatzistavrou X, Velamakanni S, DiRenzo K, Lefkelidou A, Fenno JC, Kasuga T, Boccaccini AR, Papagerakis $P$. Designing dental composites with bioactive and bactericidal properties. Mater Sci Eng C 2015; 52: 267-72.

81. Sauro S, Watson TF, Thompson I, Banerjee A. One-bottle self-etching adhesives applied to dentine air-abraded using bioactive glasses containing polyacrylic acid: an in vitro microtensile bond strength and confocal microscopy study. J Dent 2012; 40: 896-905.

82. Sauro S, Thompson I, Watson TF. Effects of common dental materials used in preventive or operative dentistry on dentin permeability and remineralization. Oper Dent 2011; 36: 222-30.

83. Kinney JH, Pople JA, Driessen $\mathrm{CH}$, Breunig TM, Marshall GW, Marshall SJ. Intrafibrillar mineral may be absent in dentinogenesis imperfecta type II (DI-II). J Dent Res 2001; 80: 1555-9.

\section{Yazışma Adresi}

Dr. Öğr. Üyesi Zeynep Aslı GÜÇLÜ

Erciyes Üniversitesi, Diş Hekimliği Fakültesi, Pedodonti A. D.

Melikgazi Mahallesi, 38039 Melikgazi/Kayseri

Tel: 05076638925

E-posta: .asliguclu@erciyes.edu.tr E-mail: mustafaozayuslu@hotmail.com 